\title{
Futebol Libertário: Compromisso Social na Medida
}

Libertarian soccer: social commitment

Fútbol libertario: compromiso social en la medida

Fábio Silvestre Silva, Francisco

Helder da Silva Oliveira,

Marcelo Arruda Piccione \&

Roberta Freitas Lemos

Núcleo de Formação e

Pesquisa do Centro de Defesa

dos Direitos da Criança e do

Adolescente de Interlagos

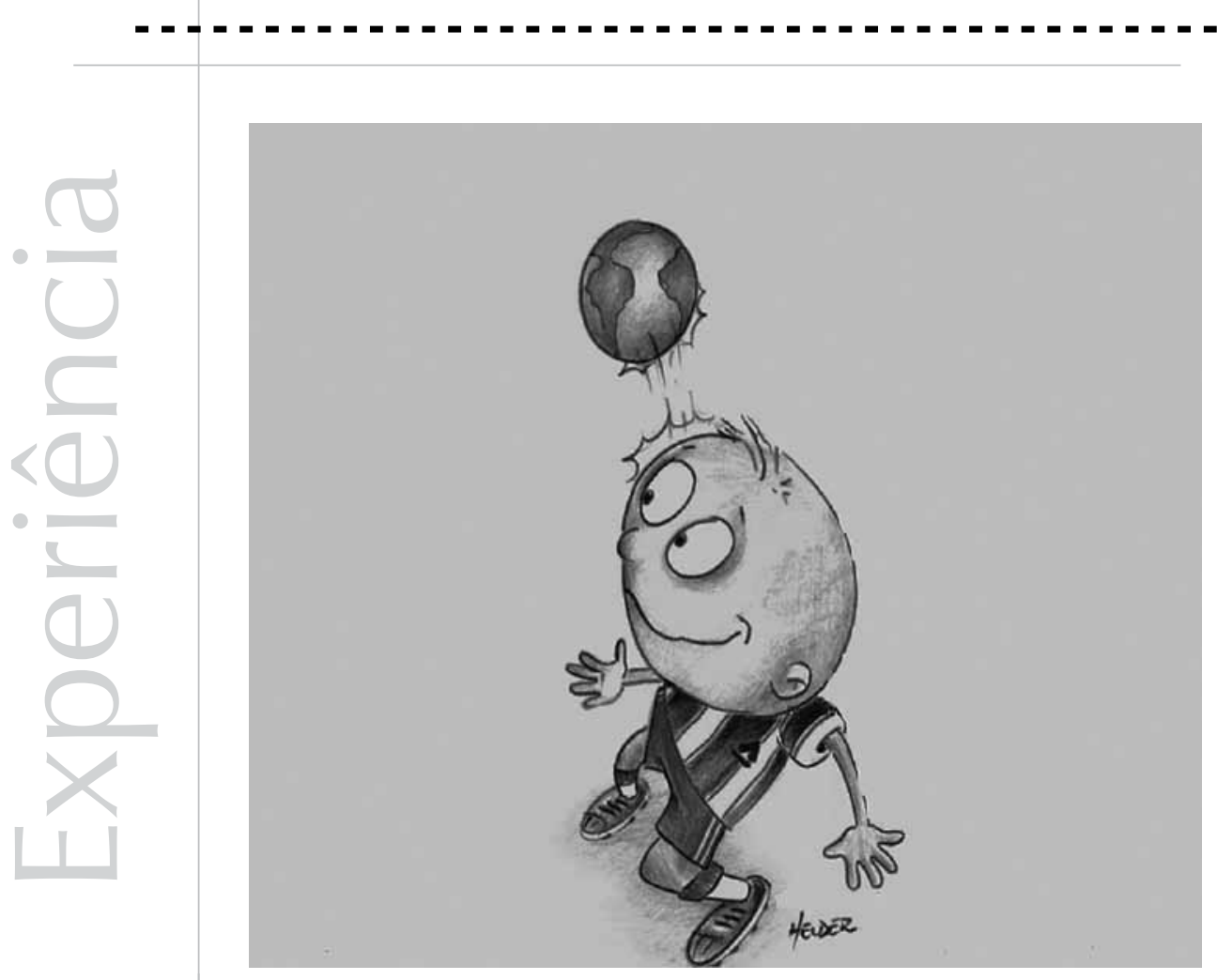


Resu mo: Baseados na Constituição de 1988 e no Estatuto da Criança e do Adolescente, de 1990, o Centro de Defesa dos Direitos da Criança e do Adolescente de Interlagos (CEDECA Interlagos) traz um relato de experiência de uma metodologia alternativa de acompanhamento de adolescentes inseridos em medidas socioeducativas em meio aberto na região da Capela do Socorro e Parelheiros. Essa proposta utiliza o futebol como meio que possibilita ao adolescente refletir sobre sua realidade e suas práticas cotidianas, reconhecendo suas possibilidades de se desenvolver como sujeito de direito e de se tornar protagonista no que diz respeito às ações que busquem sua promoção social e a construção e o exercício da cidadania ativa. É possível observar que, com esse tipo de linguagem, mais próximo do desejo desses jovens, os mesmos atribuem um novo sentido ao acompanhamento a que foram submetidos. Na lógica socioeducativa, procuram superar obstáculos no sentido de buscar cada vez mais seu protagonismo, sua autoria, para reafirmar o que o ato infracional revelou, que é a busca por ser sujeito.

Palavras-chave: Futebol. Medidas socioeducativas. Adolescente. Adolescente em conflito com a lei.

Abstract: Based on the Brazilian Constitution (1988) and on the Child and Adolescente Statute (ECA/1990, Brazilian Statute for the Protection of Children and Adolescents), the Defense Center of the Child and Adolescent's Rights (CEDECA Interlagos) has developed and applied an alternative methodology for socioeducational measures for those who work with young offenders on parole. This report concerns a particular project for the adolescents who live in Capela do Socorro and Parelheiros - districts in the city of São Paulo with several social problems that lead to high levels of social vulnerability. The project has used soccer as a means of reflection on the youngsters' reality and everyday lives. The process focuses on the opportunity they are given to develop self-consciousness as citizens who have rights. The aim of the project, therefore, is the promotion of their own social well-being, so that they may become active citizens. It is possible to see that this kind of language, closer to the desire of these adolescents, gives them a new meaning to the monitoring they have undergone. In a socioeducative point of view, they seek to overcome the obstacles in order to find out what is their increasingly prominet role, and so they reaffirm what the act of infraction pointed out, that is, their search to be subjects of their rights.

Keywords: Soccer. Socioeducative measures. Adolescent. Adolescent in conflict with the law.

Resumen: Basados en la Constitución de 1988 y en el Estatuto del Niño y del Adolescente, de 1990, el Centro de Defensa de los Derechos del Niño y del Adolescente de Interlagos (CEDECA Interlagos) trae un relato de experiencia de una metodología alternativa de acompañamiento de adolescentes inseridos en medidas socioeducativas en medio abierto en la región de Capela do Socorro y Parelheiros. Esa propuesta utiliza el fútbol como medio que posibilita al adolescente reflejar sobre su realidad y sus prácticas cotidianas, reconociendo sus posibilidades de desarrollarse como sujeto de derecho y de convertirse en protagonista en lo que se refiere a las acciones que busquen su promoción social y la construcción y el ejercicio de la ciudadanía activa. Es posible observar que, con ese tipo de lenguaje, más próximo del deseo de estos jóvenes, los mismos atribuyen un nuevo sentido al acompañamiento a que fueron sometidos. En la lógica socioeducativa, buscan superar obstáculos en el sentido de buscar cada vez más su protagonismo, su autoría, para reafirmar lo que el acto de la infracción reveló, que es la búsqueda por ser sujeto.

Palabras-clave: Fútbol. Medidas socioeducativas. Adolescente. Adolescente en conflicto con la ley.

"Passei boa parte da minha adolescência trabalhando pela manhã, indo para a escola à tarde e à noite, para a igreja. Minha relação com meu padrasto, minha mãe e meus dois irmãos sempre foi muito tranqüila. Às vezes, meu padrasto pega no meu pé, principalmente depois que fui preso por participar com meus "amigos" de um" arrastão num parque. Eu não fiz nada, só queria ter ido me divertir e, por estar junto, acabei sendo preso. Apanhei muito da polícia, e o pior é que foi de bobeira, agora cumpro essa liberdade assistida. Perdi o meu emprego num lava-rápido do diretor da escola, tive um desentendimento com uma "tiazinha" da escola e por isso desisti de continuar estudando". 
"Eu já aprendi

que esse jogo

ensina a trabalhar

em grupo, a

compartilhar

com os amigos

e a se expressar

no grupo e na

sociedade. Eu

gosto muito

de tudo isso, e,

desse jeito, estou

tentando voltar

para a escola e

tudo mais... Mas

vou fazer de tudo

para acabar logo com isso"

(D.O.A., 17 anos).
Aqui no CEDECA, o João (educador de referência que acompanha o adolescente) me chamou para jogar uma bola e acabei aceitando. A gente faz um monte de atividades e joga de um jeito diferente, que eu nunca tinha imaginado. Na roda final, a gente fala sobre o que está aprendendo. Eu já aprendi que esse jogo ensina a trabalhar em grupo, a compartilhar com os amigos e a se expressar no grupo e na sociedade. Eu gosto muito de tudo isso, e, desse jeito, estou tentando voltar para a escola e tudo mais... Mas vou fazer de tudo para acabar logo com isso" (D.O.A., 17 anos).

A Constituição de 1988, conhecida como Constituição Cidadã, é marcada pela maior participação da sociedade civil no processo de mudança para o Estado democrático de direito. Nesse cenário, muitos movimentos sociais ganharam força; dentre eles, está o movimento da infância e juventude, que obteve grandes avanços ao ganhar uma nova compreensão de cidadania, e novo paradigma (proteção integral) com a aprovação do Estatuto da Criança e do Adolescente (ECA), Lei Federal no 8069, de 13 de julho de 1990.

Segundo Costa (2003), a luta pela efetivação dos direitos da criança e do adolescente tem conseguido algumas conquistas importantes durante os últimos anos, como, por exemplo, na organização da luta contra as violações dos seus direitos. Apesar disso, ao olharmos ao nosso redor, notamos uma distância muito expressiva entre aquilo que está na legislação e o que de fato é garantido pela família, pela sociedade e pelo Estado. Nesse sentido, pode ser observada, ao estudar a realidade da criança e do adolescente que moram nas periferias de São Paulo, a ineficácia do sistema educacional que tem sido oferecido pelo Estado.
A realidade social no Brasil não é diferente, como se pode ver pelas crises que se agravam, cada vez mais, devido às relações injustas de poder que o modo de produção capitalista impõe sobre as camadas ditas "populares", tornando-as subalternas. Em outras palavras, os privilegiados que possuem o acesso à tecnologia, ao capital e ao controle de informação constroem um sistema que é capaz de domesticar e alienar a si mesmo e a milhares de crianças e adolescentes que estão confinados e quase fadados a uma vida sem perspectivas, sem o acesso a uma educação crítica e transformadora.

Segundo dados do Instituto Brasileiro de Geografia e estatística (IBGE, 2001), a proporção de pessoas abaixo da linha da pobreza era de $33,60 \%$ da população total. Se for somada a esse quadro a realidade do desemprego, da miséria, da falta de moradia adequada, da saúde e da situação de violência, aumenta muito a vulnerabilidade da criança e do adolescente. Essa vulnerabilidade potencializa os riscos de ultrapassar limites e chegar à autoria de atos infracionais que prejudicam o seu "processo peculiar de desenvolvimento", preconizado pelo Estatuto da Criança e do Adolescente (Brasil, 1990).

O ECA supera a velha visão vingativa e punitiva contida no Código de Menores ao estabelecer uma visão pedagógica e educativa. O artigo 112 do ECA define o processo de responsabilização com as medidas socioeducativas (advertência, reparo do dano, prestação de serviço à comunidade, liberdade assistida, semiliberdade, internação). São elas meios de intervenção na vida do adolescente autor de ato infracional, assim como na vida da família, na comunidade e na sociedade.

As medidas socioeducativas até hoje operacionalizadas não têm como suporte 
as políticas públicas sociais necessárias que sejam oferecidas por uma rede consolidada de serviços capaz de oferecer a retaguarda desejada para a efetivação do sistema de garantia dos direitos fundamentais. Segundo Teixeira (2003), as medidas aplicadas aos adolescentes autores de ato infracional "visam ou devem visar a superar a idéia exclusiva de controle social e assumem o caráter socioeducativo a partir do ECA".

Visando a assumir esse caráter e utilizando uma ferramenta diferenciada de trabalho, o presente estudo tem a finalidade de relatar uma experiência que usa o potencial educativo da prática esportiva, mais especificamente, o futebol, na educação não formal, como meio que possibilite ao adolescente refletir sobre sua realidade e suas práticas cotidianas. $\mathrm{O}$ estudo pretende mostrar, ainda, o reconhecimento das possibilidades de o adolescente desenvolverse como sujeito de direito e de tornarse protagonista de ações que busquem sua promoção social e a construção e o exercício da cidadania ativa. Trata-se de uma proposta de atendimento alternativo direto para adolescentes inseridos nas medidas socioeducativas em meio aberto da Capela do Socorro que divulga um novo paradigma metodológico para acompanhar e orientar os adolescentes autores de ato infracional, suas famílias e entidades de inserção.

\section{O papel dos Centros de Defesa dos Direitos da Criança e do Adolescente}

De acordo com a proposta do Sistema Nacional de Atendimento Socioeducativo (Brasil, 2006), existem, no Brasil, cerca de 39 mil adolescentes/jovens no sistema socioeducativo. Esse quantitativo representa
0,2\% do total de adolescentes na idade de 12 a 18 anos existentes no Brasil.

A realidade dos adolescentes brasileiros, incluindo aqueles no contexto socioeducativo, evidencia e exige atenção do Estado e força uma agenda de prioridades no sentido de efetivar políticas públicas e sociais, e, sobretudo, amplifica os desafios da implementação da política de atendimento aos adolescentes, já que, pelos dados apresentados, a adolescência não se encontra preservada. Para entender o universo onde se desenrola esse trabalho, há que se contextualizar o papel dos Centros de Defesa, nessa fase pós-estatuto, até chegar à entidade onde o trabalho foi desenvolvido.

Observa-se que o ECA estabelece os direitos fundamentais e ainda as linhas para ação do atendimento, visando à garantia desses direitos. Os Centros de Defesa estão inseridos no Sistema de Garantia de Direitos (Resolução 113 do Conselho Nacional dos Direitos da Criança e do Adolescente, 2006), nas linhas de ação de atendimento com responsabilidade, e, através de instrumentos jurídicos, buscam intervir na política pela defesa dos direitos da criança e do adolescente. Não atuam somente na área da defesa, mas intervêm juridicamente e garantem o acesso à Justiça, além de manter a formação e a capacitação para contribuir com a mobilização e a disseminação dos direitos aos atuantes da área da infância e da juventude.

\section{Contextualizando uma prática}

O Centro de Defesa dos Direitos da Criança e do Adolescente de Interlagos foi fundado em 1999, por um grupo de educadores sociais. Nasceu a partir da experiência acumulada durante muitos anos de trabalhos comunitários em favelas de Interlagos e com 
movimentos populares da Capela do Socorro. Identifica-se como organização de assessoria aos movimentos populares, a serviço das lutas populares organizadas nas comunidades locais, associações de moradores, entidades de atendimento e movimentos específicos da Capela do Socorro, tendo seu olhar voltado para a realidade da criança e do adolescente.

Esse centro, onde o presente trabalho foi desenvolvido, está situado na região da Capela do Socorro, e possui, em sua área de abrangência, cinco distritos do extremo sul da cidade de São Paulo: Socorro, Cidade Dutra, Grajaú, Parelheiros e Marsilac, que ocupam uma superfície de $487,8 \mathrm{~km}^{2}$, o que corresponde a 1/3 do território do Município. As análises utilizadas para contextualizar a realidade do adolescente em situação de risco social e pessoal baseiam-se no "mapa da exclusão e da inclusão" elaborado pelo Núcleo de Estudos e Pesquisas de Seguridade e Assistência Social da PUC-SP e reeditado em 2000, e o Mapa da Juventude de São Paulo, de 2003. Já nessa pesquisa, os bairros da Capela do Socorro se destacam quanto aos altos índices de exclusão social. $\mathrm{Na}$ classificação geral dos 96 subdistritos do Município de São Paulo, a Cidade Dutra ficou em $71^{\circ}$ lugar, Grajaú em 95, Marsilac em $80^{\circ}$, e Parelheiros em $96^{\circ}$.

Essa tendência pode ser explicada pela deterioração generalizada das políticas públicas sociais do Estado nos últimos anos. Sua implantação, que já é estruturalmente precária, é ainda mais reduzida na Capela do Socorro em função da localização integral da região em área de proteção aos mananciais. Além disso, o agravamento da situação da Capela do Socorro pode ser explicado em função das altas taxas de crescimento populacional, que estão significativamente acima da média de crescimento do Município.
O CEDECA Interlagos iniciou seu trabalho com liberdade assistida (LA) em 1999, quando firmou convênio com a Fundação para o Bem-Estar do Menor (FEBEM) de São Paulo para atender, naquela época, 70 adolescentes. Diante do aumento significativo do número de adolescentes envolvidos em atos infracionais, foi necessário ampliar a cada ano o número de atendimentos, chegando-se, em 2002, a atender 240 adolescentes em LA e 60 em PSC, totalizando 300 adolescentes atendidos ao mês. Para suprir essa demanda de atendimento, a equipe do CEDECA Interlagos foi redimensionada, ficando com 15 educadores sociais com formação diversificada (psicólogos, assistentes sociais, advogados, sociólogos, historiadores, etc) e dois coordenadores.

\section{O esporte como instrumento educacional e o acompanhamento das medidas socioeducativas}

Segundo Rúbio (2000), o esporte pode ser considerado um dos maiores fenômenos sociais da modernidade por atrair uma grande massa de participantes e fãs, além de agregar em torno de si um número crescente de áreas afins. A Constituição Federal e o Estatuto da Criança e do Adolescente (ECA) garantem às crianças brasileiras o direito à educação, à cultura, ao esporte a ao lazer. Como necessidades humanas básicas, esses são direitos de toda população infanto-juvenil, e não privilégio de grupos ou classes sociais. No caso do esporte, significa uma prática democratizada, ao alcance de todos, e não somente daqueles que apresentam alguma aptidão ou talento especial.

O ECA estabelece que os Municípios, com o apoio dos Estados e da União, deverão 
estimular e facilitar a destinação de recursos e espaços para programações culturais, esportivas e de lazer voltadas para a infância e a juventude.

Nas áreas esporte e lazer, os órgãos específicos responsáveis pelas políticas desses campos são também os responsáveis pelo desenvolvimento de programas coordenados com o órgão gestor das medidas socioeducativas, buscando assegurar a efetivação dos direitos (IAS, 2004).

No contexto da educação, o esporte inserese a partir de uma nova concepção. Parte-se do princípio de que esse fenômeno pode ser um método pedagógico, ou seja, um meio de desenvolvimento das diversas potencialidades humanas que supere a visão de aprender o esporte apenas enquanto técnica e instrumento de atividade corporal, e que se proponha a ser um fator de desenvolvimento integral da criança e do adolescente (IAS, 2004).

Dentre as muitas modalidades esportivas praticadas no Brasil, nenhuma outra é considerada tão popular como o futebol. Daolio (1998) escreve sobre essa modalidade esportiva a partir de uma análise cultural, e afirma que o futebol é uma forma que a sociedade brasileira encontrou para se expressar e, nesse sentido, afirma que é uma forma de prática da cidadania. Como o carnaval, o futebol, no Brasil, abre a possibilidade da expressão individualizada e livre, em uma rede de relações humanas, ocasião em que alguém pode revelar-se como é, com suas habilidades e fraquezas (Da Matta, 1982).

Desse modo, pode-se observar a potencialidade educativa do esporte e, nesse caso, em especial, do futebol na sociedade brasileira. Como já foi dito anteriormente, a prática pela prática somente não é garantia para abordar as questões acima citadas, no âmbito da infância e da juventude. Dois pontos são levantados a seguir: o planejamento das ações e a relação entre educador e adolescente, principalmente a partir da abertura que se dá nas conversações e na busca de diálogos abertos e reflexões.

O primeiro ponto remete diretamente ao cuidadoso planejamento e execução do plano de ação. No âmbito do CEDECA Interlagos, essa ação tem como embasamento teórico os quatro pilares da educação, visão organizada e trazida por Jacques Delors no relatório da UNESCO, na Conferência de Jomtiem sobre Educação para Todos, em 1990, na Tailândia, além da pedagogia libertadora de Paulo Freire.

Os quatro pilares da educação são concebidos como territórios do desenvolvimento de potenciais; as quatro aprendizagens são integradas e precisam ser identificadas como experiências para a vida. $\mathrm{O}$ aprender a ser, aprender a conviver, aprender a conhecer e aprender a fazer nortearam o desenho de um conceito de competências, atitudes e habilidades. No Brasil, o Instituto Ayrton Senna (IAS) foi um dos pioneiros no trabalho com educação pelo esporte. A noção de competências une o conhecimento aos valores, às atitudes e às habilidades para concretizar as ações. Competências pessoais (aprender a ser), sociais (aprender a conviver), cognitivas (aprender a conhecer) e produtivas (aprender a fazer) são utilizadas como pontos de referência do trabalho dos educadores no momento de planejamento, execução e avaliação do trabalho (IAS, 2004b).

O segundo ponto aborda diretamente a relação educador e adolescente. Nesse 
processo, a mediação/intervenção tornase fundamental para estabelecer a relação entre a atividade esportiva e os conceitos a ela inerentes. Buscamos, para isso, apoio em Paulo Freire (2003) quando ensina que "ensinar não é transferir conhecimentos, mas criar as possibilidades para a sua própria produção ou a sua construção". Continua afirmando o autor que o educador, ao ensinar, deve "estar aberto a indagações, à curiosidade, às perguntas dos educandos, às suas inibições, um ser crítico e inquiridor, inquieto em face da tarefa" (p. 47). Assim, nesse contexto, por mediação/intervenção, compreende-se a capacidade de elucidar e aclarar as inter-relações da dinâmica esportiva, facilitando e explorando tais relações entre os atores participantes. Os mediadores, por sua vez, são os profissionais ligados à atividade esportiva (como os técnicos), que trabalham com outros profissionais para que as especificidades de cada área possam complementar-se.

De acordo com Marques e Kuroda (2000), o desenvolvimento humano deve ser pensado como um processo que se estabelece entre uma relação dialética do sujeito com a realização da tarefa que se apresenta. Criança e adolescente devem contar com condições prévias e básicas no que se refere aos domínios motores, emocionais, cognitivos e sociais para o desempenho da tarefa. Devem somar ao seu repertório as melhores condições desses mesmos domínios enquanto realizam as tarefas, pois a prática de atividades que estimulam capacidades cognitivas, sociais e motoras, entre outras, constrói seu aprendizado e estimula seu desenvolvimento.

A mediação/intervenção do educador físico nesse processo envolve questões relacionadas à prática esportiva, tais como a importância da formação de uma cultura corporal, o autoconhecimento de potencialidades e os limites do corpo, a formação da base motora para a execução de movimentos durante a prática esportiva, o oferecimento de experimentação para futuras escolhas, etc. O papel dos educadores sociais é de facilitar e mediar a troca de experiências nesses diversos momentos, buscando elaborar atividades que objetivem ressaltar a integração, a comunicação e a cooperação. O educador busca orientar o adolescente para a vida, contribuindo, por esse meio, para questões mais amplas e auxiliando na construção da identidade do indivíduo praticante da atividade física e do esporte (Rúbio, Queiroz, Montoro, Marques, \& Kuroda, 1999).

Assim sendo, configura-se a importância de um profissional que possa contribuir para a mediação das relações que a criança e o adolescente estabelecem com o outro e com o mundo, em que os papéis do técnico/ educador/psicólogo vão além da simples reprodução de um modelo pré-concebido, contribuindo para a formação de indivíduos não apenas em relação aos conhecimentos adquiridos mas também para a realização como ser humano, preparando-o para enfrentar os desafios impostos pela sociedade (Marques \& Kuroda, 2000).

\section{A entrada em campo}

O Futebol Libertário teve início em 2005, após uma experiência prévia em um projetopiloto que criou uma metodologia específica que utilizou o futebol como elemento educativo crítico, ou seja, sem fazê-lo perder a sua especificidade enquanto esporte/ jogo, mas aproveitá-lo como um instrumento de transformação social. Para isso, foi necessário que os envolvidos nesse processo pedagógico de aprendizagem do futebol incorporassem, 
ao mesmo tempo, através da prática e da reflexão, uma nova concepção de esporte e de relacionamento humano, calcada em princípios que combatem o individualismo, a vitória a qualquer custo, o autoritarismo e as mais diversas expressões de discriminação e preconceito (racial, sexual, cultural, etc.), entre outros valores que nos distanciam de uma sociedade verdadeiramente justa e democrática.

Desse projeto-piloto, resultou uma proposta metodológica que foi utilizada na implantação do futebol como forma de acompanhamento de medida socioeducativa em meio aberto. Atualmente, o Futebol Libertário atende cerca de 80 adolescentes de 12 a 18 anos, divididos em três núcleos: Cidade Dutra, Grajaú e Parelheiros. Dentre os adolescentes, estão tanto aqueles que cumprem medida socioeducativa quanto alguns que não cumprem, partindo do princípio de que também se quer acessar o entorno dos adolescentes em medida socioeducativa, e, por esse motivo, os adolescentes são sempre incentivados a convidar amigos e familiares para integrarem o grupo.

\section{Jogando o jogo}

A análise dos encontros procura fazer uma relação entre o coletivo e o individual, dando ênfase à construção das relações da convivência grupal, nas suas diferentes etapas. Na proposta metodológica que foi denominada de PAIS, existem quatro etapas que se complementam cotidianamente: preparando o terreno, analisando o jogo, imaginando o futuro e saindo de campo. No entanto é preciso separá-las aqui didaticamente para maior compreensão. Essas etapas procuram seguir o que Teixeira (2003) chamou de "organização do projeto".
Preparando o terreno - Trata-se dos primeiros momentos para a formação do grupo, quando se inicia a construção dos vínculos. É entendido como o momento da construção da estrutura e da identidade dessa formação, e, fundamentalmente, é uma etapa de esclarecimento do funcionamento geral das atividades assim como da formação do que se combina para a convivência.

Analisando o jogo - Essa etapa é marcada por uma reflexão mais aprofundada de si mesmo e da coletividade a que se pertence, e tem como foco os direitos fundamentais e as questões da territorialidade. É o momento marcado para olhar para fora e analisar toda a situação. Essa fase leva os adolescentes e a equipe a refletir sobre o local de moradia, o transporte e as redes que deveriam funcionar atendendo ao cidadão. É o momento de confronto de realidades.

Imaginando o futuro - Essa etapa diz respeito aos sonhos e perspectivas dos adolescentes como um momento de elaboração de um mini-projeto, e cria a cultura de projetarse. É o momento crucial de redefinição ou de confirmação do plano de atendimento individual e do estabelecimento de metas concretas e possíveis. isto é, o futuro norteia as práticas do presente.

Saindo de campo - Essa é a etapa de concretude de todo o trabalho, que visa à saída dos adolescentes da medida. $\mathrm{O}$ desligamento do projeto é tratado como processo, e representa o momento da autonomia e da ação. É o momento da avaliação das próprias conquistas e decisões que foram tomadas, pois é importante que o projeto consiga auxiliar no desenvolvimento das competências trabalhadas.

Estrategicamente, é importante dizer que os encontros foram organizados da seguinte forma: 
Ponto de encontro: sede do núcleo do CEDECA Interlagos em Cidade Dutra, Grajaú ou Parelheiros.

Diálogos abertos (roda inicial): momento em que são colocados os objetivos do dia e das atividades e em que há uma retomada das atividades anteriores; serve ainda como termômetro dos humores do dia e da dinâmica do grupo.

Aquecimento: preparação do organismo para a atividade a seguir. Visa a obter o estado ideal psíquico e físico, a preparação para os movimentos e principalmente a prevenir as lesões.

Alongamento: prepara os músculos para as exigências que virão a seguir, protegendo e melhorando o desempenho muscular.

Atividade(s) principal (is): atividade realizada com maior vigor físico, também planejada, para alcançar os objetivos do dia.

Diálogos abertos (roda final): momento de avaliação do dia e das reflexões sobre os aprendizados. Momento de fala e escuta.

Lanche e distribuição dos passes: momento de confraternização e responsabilidade, pois os jovens eram responsáveis por esse momento.

\section{O gol}

Durante o decorrer da experiência, tentou-se estimular o conhecimento dos próprios limites e potencialidades, um aspecto abordado por todo o trajeto de acordo com o momento em que cada adolescente passava. Outras competências pessoais foram trabalhadas de acordo com a demanda do grupo, como respeitar a si mesmo, argumentar acerca dos fatos, expressar e manifestar idéias e proposições, incluindo a opinião em relação aos participantes.

Com relação às competências pessoais, o Grupo do Futebol Libertário tem mantido a busca, dentro da metodologia específica, de aprimorar uma seqüência pedagógica de desenvolvimento pessoal que privilegie um projeto de vida para o adolescente, resgate o autoconhecimento e desperte as perspectivas, através de maior participação nos planejamentos diários, dentro dos espaços das atividades, onde se possa contextualizar a busca de objetivos e as estratégias para alcançá-los, incluindo direitos, interesses e escolhas. Dessa forma, a avaliação se faz dentro dos próprios discursos e produções feitas.

A possibilidade da construção de um projeto de vida próprio é um dos aspectos mais importantes a serem computados. Sendo assim, o processo tem início a partir de planejamentos feitos em grupo para então refletir, através de discussões contextualizadas, sobre estes na vida cotidiana e na possibilidade de realização.

Com isso, conseguimos estimular a autonomia e o autoconhecimento de cada um deles em busca do seu próprio objetivo, reconhecendo limites e potencialidades e construindo possibilidades.

A autonomia é outra competência que marcou alguns momentos desse processo. Essa autonomia pode ser vista também no grupo, uma vez que os adolescentes buscam e discutem suas necessidades não só para benefício próprio mas também em favor do próprio coletivo, como na produção de combinados (regras) de convivência e participação constante na produção dos planejamentos semanais. 
Em relação ao desenvolvimento de competências, no que diz respeito às competências cognitivas, que correspondem à aquisição de conhecimentos e informações, foi verificada uma efetivação, através de uma maior participação e assiduidade nos eventos da instituição. Por outro lado, o interesse por pesquisa vem sendo trabalhado através dos projetos de promoção e mobilização social e desenvolvimento pessoal (como a significação do futebol extracampo, do alcance político de uma Copa do Mundo e do esporte na cultura brasileira, por exemplo), que se baseiam na necessidade de incluir possibilidades de acesso ao conhecimento. Quanto a isso, a avaliação é positiva, e os adolescentes buscam cada vez mais informação e desenvolvem produtos individuais, como, por exemplo, a produção de currículos.

Ainda se tratando do aprender a conhecer, despertar a consciência de direitos e deveres é mais um foco de trabalho, e entendese que esse é um fator importante que se reflete no desenvolvimento socioeducativo e que é avaliado, produtivamente, através da busca de encaminhamentos aos serviços públicos por parte dos participantes. Diante disso, os adolescentes, cotidianamente, vêm procurando informações sobre saúde (unidades de atendimentos médicos), educação (encaminhamentos escolares) e profissionalização (equipamentos que atendam à prestação de serviço à comunidade), fato esse que teve início e que vem aumentando, também, à medida que o educador mantém um vínculo de trabalho mais próximo do adolescente, em que este se encontra fortalecido pela participação efetiva nas atividades diárias do Futebol Libertário. Em relação à busca de direitos, especificamente no que diz respeito à inclusão escolar (tema indispensável quanto à parceria educativa), percebeu-se que houve um significativo aumento no quadro de adolescentes matriculados. A grande maioria dos adolescentes inseridos no Futebol Libertário está matriculada e freqüenta a escola, e os demais estão à procura de escolas para a realização da matrícula.

Consideramos que tais intervenções aliadas a atividades práticas foram parte de um processo gradual de responsabilização e de cumprimento efetivo da medida socioeducativa, ainda pontuando essa mudança de comportamento em adolescentes que anteriormente manifestavam muita dificuldade no comparecimento regular da própria atividade.

Quanto às competências sociais, há, ainda, tendo em vista o estabelecimento de relacionamento interpessoal sadio, menor índice de discussões (brigas, xingamentos, entre outros) entre os adolescentes e maior índice de ações cooperativas. Em relação ao ato infracional (entendido aqui como fato social), o descumprimento da medida socioeducativa tem apresentado menor porcentagem (atualmente, 4\% dos adolescentes inseridos no Futebol Libertário), assim como a reincidência.

Em referência às competências produtivas, a metodologia adotada vem trabalhando a questão da realização e da estruturação de um produto final, idéia essa que tem tido grande participação dos adolescentes no que diz respeito à organização de campeonatos e à busca de atividades mais protagônicas, no contexto do planejamento.

Dentro disso, muitas ações foram realizadas através dessa dinâmica de atendimento e produção. Nesse processo, os adolescentes 
elaboraram e participaram de eventos na comunidade, no CEDECA Interlagos e em outras instituições. Discutiram e se sensibilizaram, em dado momento, sobre o empoderamento e a busca dos seus direitos, previstos no Estatuto da Criança e do Adolescente (ECA), como a busca de locais na comunidade para prática esportiva, entre outros.

Podem ser citadas as atividades planejadas e organizadas pelos participantes, em conjunto, como, por exemplo, o campeonato para crianças da comunidade, coletivos com os educadores do CEDECA Interlagos, amistosos com outras instituições parceiras, oficinas educativas sobre o Estatuto da Criança e do Adolescente em parceria com outro projeto e mutirão para arrumar um campo de futebol no Distrito do Grajaú, entre outros.

Quanto à questão familiar, numa perspectiva quantitativa de atendimentos e visitas familiares, assim como nos relatos de telefonema e na busca de um dado avaliativo mais amplo dos aspectos sociais (aprender a conviver), principalmente quanto ao fortalecimento dos vínculos familiares, constata-se que há um compromisso maior por parte dos parentes em acompanhar o adolescente. Esse fato pôde ser constatado pelo aumento do número de atendimentos com o objetivo de obter esclarecimentos tanto da questão jurídica da medida socioeducativa quanto com relação ao conhecimento de seus direitos e deveres, com a inclusão, principalmente, de questões relativas à família, à escola e à saúde.

Há ainda uma busca pela avaliação das demandas específicas do núcleo familiar de cada adolescente, assuntos abordados nos próprios atendimentos e que contam com a possibilidade de encaminhamentos tanto para o Grupo de Apoio à Família, que tem o objetivo focado na questão da promoção social, quanto para o Núcleo de Defesa, que trabalha a questão da proteção jurídico-social nesse Centro de Defesa.

Apesar dos dados e avaliações acima descritos, entende-se que existe ainda certa dificuldade diante do envolvimento dos familiares dos adolescentes. Dessa forma, pensando nesse quadro apresentado, na participação observada e na importância do trabalho específico (buscando um olhar amplo que inclui educando, família e comunidade), há também a necessidade de se elaborar novas estratégias específicas direcionadas para essa relação.

\section{Considerações finais}

Sendo a segunda etapa de um processo de consolidação de metodologia, fica evidente que o campeonato não termina aqui, com essa partida. A cada dia, a experiência relatada se transforma em passado, e cada um dos participantes vive sua vida. Mesmo assim, é possível perguntar sobre a construção da subjetividade e sobre qual será o futuro desses adolescentes, tendo em vista a limitação expressa nesta abordagem.

Os adolescentes que participaram deste trabalho viveram na "pele" a representação que atribui ao esporte a pior conotação de "quem não tem o que fazer", que é impregnada dos discursos da sociedade e reproduzida por algumas famílias que acompanharam o processo. 
O projeto aqui exposto ofereceu a oportunidade de aprender - até mais do que foi capaz de ensinar - o fato de que os adolescentes participantes demonstram que a idéia libertária trabalhada é a ruptura para experimentar uma outra possibilidade de ser, para além das limitações, para além das privações. Mostram que, nessa lógica libertária, "nós podemos ser gente, onde somos pessoas", e que podem negociar e falar das suas experiências.

Ao considerar o contexto social de cada um no conjunto, é possível afirmar que há a construção de um saber coletivo e a composição de um diálogo aberto com os adolescentes, o que mostra a "razão de ser" do conhecimento. Nesse sentido, à medida que se lhe apresentam novas jogadas e outras possibilidades, acaba-se criando um "rito de passagem" desse adolescente pelo Futebol Libertário, pela liberdade assistida, pela prestação de serviços à comunidade e pelo próprio CEDECA Interlagos.

Oesporte como um instrumento socioeducativo é uma prática utilizada em inúmeros projetos sociais direcionados a crianças e adolescentes em situação de vulnerabilidade. A intervenção nas medidas socioeducativas com adolescentes inseridos em medidas em meio aberto, porém, apresenta-se como uma iniciativa pioneira, e, como tal, trouxe um grande desafio devido às especificidades dos atores envolvidos adolescentes, educadores, psicólogos.

Uma das descobertas importantes foi possibilidade de aglutinar diversas experiências de Psicologia com o esporte, uma atividade naturalmente atraente, para facilitar a adesão dos adolescentes. Aderindo à prática esportiva, os adolescentes estão mais próximos dos profissionais envolvidos, que encontram, muitas vezes, as portas abertas para desenvolver outros trabalhos. Vale dizer, também, que essa técnica expressiva é uma experiência socializante, já que permite ao adolescente entrar em contato com regras, limites e disciplina.

A produção acadêmica sobre esporte no Brasil tem aumentado significativamente, na última década. O mesmo crescimento não se verifica na prática do esporte educacional voltado para os projetos sociais. No entanto, a dimensão cultural do esporte e da atividade física em geral como atividade de autoexpressão, seus benefícios para a saúde e para a formação da personalidade, sua capacidade de aglutinar pessoas e promover a cooperação são características largamente reconhecidas, que orientam a formulação dos planos pedagógicos de muitas escolas e da política de oferta de atividade de lazer de muitas instituições de caráter público e social.

Este trabalho, ao buscar uma fundamentação teórica que nos aproxime do conceito de educação e cidadania no contexto socioeducativo dos movimentos populares, tenta contribuir com a intervenção social mais coerente e conseqüente pelos sujeitos que atuam em tais organizações. Mesmo diante das muitas limitações encontradas, é possível observar que, com esse tipo de linguagem mais próximo do desejo desses jovens, todo o trabalho de acompanhamento é facilitado, e eles atribuem um novo sentido ao acompanhamento a que foram submetidos. Na lógica socioeducativa, procuram superar obstáculos no sentido de buscar cada vez mais seu protagonismo, sua autoria, para reafirmar o que o ato infracional apontou, que é a busca por ser sujeito. 
Fábio Silvestre Silva*

Psicólogo, especialista em Psicologia do esporte, mestre em Educação pela Universidade de São Paulo e coordenador do Projeto Futebol Libertário

\section{Francisco Helder da Silva Oliveira}

Artista plástico com pós-graduação em Atendimento Sistêmico a Famílias e Redes pela University College Trömso - Noruega e diretor do Centro de Defesa dos Direitos da Criança e do Adolescente de Interlagos

\section{Marcelo Arruda Piccione}

Estudante de Psicologia e educador social que acompanha o Projeto Futebol Libertário

\section{Roberta Freitas Lemos}

Psicóloga, bacharel em Esporte, mestre em Psicologia experimental: Análise do Comportamento, técnica que acompanha o Projeto Futebol Libertário e responsável pelo Núcleo de Formação e Pesquisa do Centro de Defesa dos Direitos da Criança e do Adolescente de Interlagos

*Endereço para envio de correspondência:

Rua Nossa Senhora de Nazaré, 51, Cidade Dutra, São Paulo - SP - Brasil CEP 04805-100

E-mail: cedeca.inter@uol.com.br 
Brasil. (1990). Estatuto da Criança e do Adolescente. Lei Federal n. 8.069, de 13 de julho de 1990. Brasília, DF: Secretaria do Estado dos Direitos Humanos, Departamento da Criança e do Adolescente.

Brasil. (2002). Constituição Federal. Brasília, DF: Senado Federal.

Brasil. (2006). SINASE - Sistema nacional de atendimento socioeducativo. Brasília, DF: Secretaria Especial dos Direitos Humanos, Subsecretaria dos Direitos da Criança e do Adolescente.

Conselho Nacional dos Direitos da Criança e do Adolescente. (2006). Resolução n. 113. Brasília, DF; Autor.

Costa, C. H. (2003). O Abuso sexual doméstico e a perspectiva da proteção integral. Dissertação de Mestrado em Direito Processo Civil, Faculdade de Direito, Pontifícia Universidade Católica de São Paulo, São Paulo.

Da Matta, R. (1982). Universo do futebol: esporte e sociedade brasileira. Rio de Janeiro: Pinakotheke.

Daolio, J. (1998). Las contradicciones del futbol brasileño. Lecturas: Educación Física y Deportes, 3(10). Recuperado em 10 de maio de 2007, de http://www.efdeportes.com/ efd10/daolioe.htm

Freire, P. (2003). Pedagogia da autonomia: saberes necessários à prática educativa. São Paulo: Paz e Terra.
Instituto Ayrton Senna. (2004a). Educação pelo esporte: educação para o desenvolvimento humano pelo esporte. São Paulo: Saraiva.

Instituto Ayrton Senna. (2004b). Educação para o desenvolvimento humano. São Paulo: Saraiva.

Instituto Brasileiro de Geografia e Estatística. (2001). Departamento de população e indicadores sociais. Rio de Janeiro: Autor.

Marques, J. A., \& Kuroda, S. J. (2000). Iniciação esportiva: um instrumento para a socialização e a formação de crianças e jovens. In K. Rubio (Ed.), Psicologia do esporte: interfaces, pesquisa e intervenção. São Paulo: Casa do Psicólogo.

Rubio, K. (2000). O pontapé inicial. In K. Rubio (Ed.), Psicologia do esporte: interfaces, pesquisa e intervenção. São Paulo: Casa do Psicólogo.

Rubio, K., Queiroz, C., Montoro, F. C., Marques, J. A., \& Kuroda, S. J. (1999). Iniciação esportiva e especialização precoce: as instâncias psicossociais presentes na formação esportiva de crianças e jovens. Revista Metropolitana das Ciências do Movimento Humano, 4(1).

Teixeira, M. L. T. (2003). As histórias de Ana e Ivan: boas experiências em liberdade assistida. São Paulo: Fundação Abrinq. 